\title{
The long and winding road of eHealth. The service ecosystem perspective
}

\author{
Roberta Sebastiani and Alessia Anzivino \\ Catholic University of the Sacred Heart, Milan, Italy
}

\begin{abstract}
Purpose - This paper aims to investigate the eHealth ecosystem's evolution during the coronavirus disease 2019 (COVID-19) pandemic and its effects on the progression of care for patients with chronic cardiovascular disease.

Design/methodology/approach - To attain the aim of the study, this study chose to adopt a qualitative method that matches the complexity of the issue. The study was conducted in a real context through 44 face-to-face semi-structured interviews of key informants at different levels of the Italian eHealth service ecosystem, via Microsoft Teams. The interviews were carried out from June 2020 to January 2021 . In this research, we adopted an abductive approach that enabled a process where the theoretical framework and the data analysis evolved at the same time.

Findings - The study results were used to develop a conceptual framework that considers the key factors enabling and constraining the evolutionary process of the eHealth service ecosystem. In particular, the drivers that emerged from the study were actor role empowerment, actornetwork engagement and resource reconfiguration while the inhibitors were inter- and intra-actor misalignment, resource myopia and the platformisation gap. The findings also revealed the pivotal role of the meso level in the development of the eHealth service ecosystem, boosted by the COVID-19 pandemic.

Originality/value - By adopting a service ecosystem perspective, this paper contributes, at both a theoretical and a managerial level, to a better understanding of the dynamics related to the diffusion of eHealth. The study identifies the main issues that researchers, managers and policymakers should address to support the evolution of the eHealth service ecosystem, with particular regard to chronic cardiovascular disease.
\end{abstract}

Keywords COVID-19, eHealth, Service ecosystem, Chronic disease, Drivers, Inhibitors

Paper type Research paper

\section{Introduction}

The coronavirus disease 2019 (COVID-19) pandemic has challenged global health-care ecosystems (Brodie et al., 2021; Finsterwalder and Kuppelwieser, 2020). It has affected people's private lives, social relationships and the economy. It has particularly affected health-care service providers and patients, causing service mega-disruptions or "unforeseen service market disturbances caused by a pandemic" (Kabadayi et al., 2020, p. 810).

The situation suspended ordinary hospital activities and seemed to have forced hospitals to focus only on COVID-19 patients. Doctor appointments and visits and non-urgent interventions for other patients, including chronic cases, have been postponed or cancelled. A reduction of patient transfers to hospitals during the pandemic and the limitation of these transfers only to the most urgent cases have required new solutions for adequate health-care service provision to both COVID-19 and non-COVID-19 patients. Patients with a chronic disease particularly need continuous care; ensuring treatment continuity improves these patients' quality of life and reduces the negative effects, due for example to non-adherence

The current issue and full text archive of this journal is available on Emerald Insight at: https://www.emerald.com/insight/0885-8624.htm

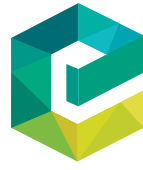

Journal of Business \& Industrial Marketing 37/10 (2022) 2036-2049

Emerald Publishing Limited [ISSN 0885-8624] [DOI 10.1108/JBIM-02-2021-0107] to therapies and to confusion on the medication patients might actually be taking at home, of their condition on society as a whole (Corbett et al., 2020).

The Italian Cardiology Society has noted that since the start of the current pandemic, the mortality from heart attacks has tripled, and in most cases, this has been linked to nontreatment or delayed treatment (De Rosa et al., 2020). In this period, eHealth, where used, has been proven to be an effective and efficient way of delivering personalised and continuing cure to people with chronic diseases, taking care of them by screening, monitoring and managing them at home and handling their follow-up by remote control (Cormi et al., 2020).

The World Health Organization (WHO, 2018) defines eHealth as the use of information and communication technology (ICT) for health. Through the use of telecommunication and digital tools, eHealth aims to provide services for first aid, emergency

(C) Roberta Sebastiani and Alessia Anzivino. Published by Emerald Publishing Limited. This article is published under the Creative Commons Attribution (CC BY 4.0) licence. Anyone may reproduce, distribute, translate and create derivative works of this article (for both commercial and non-commercial purposes), subject to full attribution to the original publication and authors. The full terms of this licence may be seen at http://creativecommons.org/licences/by/4.0/legalcode

The authors would like to thank the special issue editorial team and the anonymous reviewers for their valuable comments and feedback on earlier versions of this article.

Received 19 February 2021

Revised 6 June 2021

Accepted 12 August 2021 
medicine, operations centres and the like to expand the use of specialised skills at the community level for a more qualitative and safe distribution of health care (Kraus et al., 2021; Tuzii, 2017). Moreover, eHealth aims to guarantee continuous monitoring at home, to improve services and reduce costs through the optimal use of ICT in the health-care system, to promote learning of these subjects and to ensure telematic dissemination of information to patients (WHO, 2018) through the integration of various actors, institutions and health-care organisations (Melchiorre et al., 2018).

Nowadays, digital innovation plays a primary role in health care, providing new tools and opportunities, actively engaging patients, clinicians and practitioners and promoting time and resource effectiveness (Russo Spena and Mele, 2019). New ICT solutions are fundamental for co-creating value by delivering health-care services that people with chronic diseases may find difficult to access, reducing hospital visits, developing programmes that patients can implement after they come back home, monitoring patient status at home and increasing hospital programme efficacy (Farabi et al., 2020). Digital technologies also help rationalise different and specialised resources and provide the data needed to create databases and validate protocols via tracking and monitoring. There are challenges, however, in managing digital technologies and telemedicine in health care, such as patient resistance and professional and patient training and privacy issues (Laurenza et al., 2018; Thielst, 2011).

In the past 20-30years, eHealth has been a core topic of numerous programmes at the European, national, regional and local levels. These programmes have aimed to increase the widespread use of digital health tools among patients, clinicians, caregivers and citizens to improve individual and societal well-being, quality of care and health sector productivity (Melchiorre et al., 2018).

Before the pandemic, eHealth was used to provide healthcare services to people with cardiovascular diseases or to candidates for such, particularly for prevention, rehabilitation, disease management, follow-up and palliative care (Wade and Stocks, 2017). In addition, some studies have confirmed that in treating cardiovascular diseases, telemedicine improves the socalled quality-adjusted life years, reduces mortality and hospitalisation rates, the number of outpatient visits and hospital stays and enhances health-care services (Farabi et al., 2020; Cichosz et al., 2016). Despite these initiatives and the technological solutions that have been adopted during the current pandemic, however, eHealth diffusion remains an ongoing process in the health-care service ecosystem, especially in relation to people with chronic diseases.

The service-dominant (S-D) logic lens may help us better understand how eHealth helps co-create value, thus impacting the evolution and reconfiguration of the health-care service ecosystem itself (Vargo et al., 2020; Frow et al., 2016), which in this complex situation needs to be flexible, agile and fluid. According to S-D logic, eHealth results in a complex multiactor ecosystem in which different elements and behaviours interact with one another, and where the heterogeneity of the actors determines not only new ways of interactions and value creation between them but also the shape of the ecosystem itself (Hanlon et al., 2017; Chi and Demiris, 2015). The active roles of the different actors support the introduction of new resources and different resource combinations, co-creating value both for the actors and the other ecosystem players (Brodie et al., 2021; Finsterwalder and Kuppelwieser, 2020; Kuppelwieser and Finsterwalder, 2016) and thus contributing to the evolution of the broader health-care service ecosystem.

While the topic of health-care system development has been the object of much research before and during the pandemic (Brodie et al., 2021; Kraus et al., 2021; Patrício et al., 2020; Russo Spena and Mele, 2019), the eHealth ecosystem's evolution during the COVID-19 pandemic and its effects on the progression of care for people with chronic diseases, particularly cardiovascular diseases, have been objects of minimal research to date. As such, our study investigated how this evolution occurs in terms of the actors involved, the resource integration practices and the impact of such evolution on the different levels of the service ecosystem.

The present study adopted a qualitative approach based on 44 in-depth interviews of different actors in the Italian eHealth service ecosystem. The data obtained were triangulated with those derived from participatory observation and from the analysis of secondary data. The data were collected in parallel, and the various sets of results were interpreted concurrently to draw valid conclusions regarding the research problem.

This paper proposes a conceptual framework that explains the effects of the COVID-19 pandemic on the development of the Italian eHealth service ecosystem, by highlighting the drivers and inhibitors of change processes in eHealth.

The research contributes to both theory and practice. At the theoretical level, our work expands the application of the S-D logic and the service ecosystem perspective in the eHealth sector. At the managerial level, our work supports both policymakers and managers as it explores the key issues where intervention is needed to facilitate and accelerate the process of the evolution and diffusion of eHealth.

The article is structured as follows. The next sections review the literature regarding health care and eHealth service ecosystems, followed by the literature on the impact of the COVID-19 pandemic on people with cardiovascular diseases and the role of eHealth. The method that was used by the study is then described. The findings from the qualitative research are then discussed, and the study conclusions and the implications of our findings for managers and policymakers are presented.

\section{A service ecosystem perspective of eHealth}

The devastating COVID-19 emergency has reinforced the need to look at eHealth as a valuable resource for the future of national health-care systems and has certified how this solution can be beneficial in maintaining continuity of diagnosis and care and in guaranteeing the sustainability of the pertinent systems. The issue of eHealth and digital technology's impact on the health-care sector over the past 20 years (Ford et al., 2017; Tuzii, 2017) has long been the focus of numerous actions at the European, national, regional and local levels, with the aim of disseminating eHealth as a customised tool for operators, patients and citizens to improve the quality of care and health sector productivity.

In 2012, the European Commission (EC) developed a strategic plan to break down the barriers to telemedicine's extensive use in European health systems (EC, 2012). The goal 
was to offer patients more widespread services and medical care that would allow greater adherence to the treatment plan, better compliance with laboratory targets and clinical outcomes and more comprehensive control of the state of health. During the pandemic, the not-insignificant benefit of ensuring continuity of care while also ensuring social distancing complements the aforementioned advantages of telemedicine.

Despite the interest in and acknowledgement of the urgency of providing eHealth solutions, there remains the question of why there is a delay in its widespread diffusion and adoption in the different local health-care systems (Kraus et al., 2021; Melchiorre et al., 2018). Remarkably, 20 years ago, in 2001, Eysenbach already highlighted how eHealth can be considered a "field in the intersection of medical informatics, public health and business, referring to health services and information delivered or enhanced through the Internet and related technologies" (Eysenbach, 2001, p. 1). He added that:

[i]n a broader sense, the term characterises not only a technical development but also a state of mind, a way of thinking, an attitude and a commitment for networked, global thinking to improve health care locally, regionally and worldwide by using information and communication technology (Eysenbach, 2001, p. 1).

More recently, eHealth has resulted in a complex, multi-actor system composed of heterogeneous elements, behaviours and interactions that combines health care and social needs, enables better care integration between the different actors at all levels and provides blended care programs (Melchiorre et al., 2018). This multi-actor perspective helps in considering the interactions between the different players of the eHealth ecosystem (e.g. patients, families, caregivers, doctors, hospitals, start-ups, public institutions) driven by the spread of digital technologies and their use by these different players to co-create value and transform the traditional health-care ecosystem (Kraus et al., 2021; Verhoef et al., 2021).

By adopting the S-D lens, we can explore eHealth as a service ecosystem consisting of interdependent networks of multiple interconnected actors who interact directly or indirectly with one another (Botti and Monda, 2020; Ng and Wakenshaw, 2018). The ecosystem emerges and develops because it is a "relatively self-contained, self-adjusting system of resource-integrating actors connected by shared institutional arrangements and mutual value creation through service exchange" (Vargo and Lusch, 2016, pp. 10-11). This perspective offers a more systemic and holistic understanding of how value co-creation occurs in the eHealth system, supporting its evolution. Furthermore, it provides relevant insights into how the heterogeneous actors interact with one another to influence and institutionalise the value co-creation process within the same service ecosystem (Pop et al., 2018). Value creation is always a collaborative and interactive process occurring in the context of a unique set of multiple exchange relationships among the actors (Vargo and Lusch, 2016). In eHealth, these actors may vary from citizens and patients to clinicians and care providers, and from payers, policymakers and governments to vendors, suppliers and commercial partners such as telecommunication companies, electronics and ICT tool manufacturers, device manufacturers, the companies in the pharmaceutical industry and start-ups. The service ecosystem is organised in three levels (Sebastiani and Anzivino, 2021), as shown below:
1 Micro level: Individual actors (e.g. cardiologists, clinicians, ICT managers, eHealth sales representatives, professional nurses, caregivers, patients, family doctors).

2 Meso level: Intra-organisational actors (e.g. private and public hospitals, clinics, local health-care organisations, technology providers, patient communities, health tech start-ups, information providers, technology consultants).

3 Macro level: Government actors (e.g. government agencies, WHO, EC, the European Society of Cardiology, the Ministry of Health, the Italian Federation of Cardiology, the Italian National Institute of Health).

An integrated system-wide view of eHealth allows us to deepen the mechanisms that enable the provision of a range of consumer-centric services by coordinating the multiplicity of actors engaged in eHealth through technology platforms. These digital platforms act as a digital backbone, supporting and facilitating resource integration among the different actors to share diagnosis decisions and e-therapies and to create participative medical research and e-patient communities (Kraus et al., 2021; Belliger and Krieger, 2018). For example, it allows both historical and real-time data exchange and gives the actors access to personalised services, such as on-demand interactions with caregivers and analytical modelling of patients' tailored treatment paths.

One of the main issues related to the widespread adoption of eHealth practices concerns the complexity of the interactions across and between the different levels of the health-care service ecosystem (Frow et al., 2019). The pandemic has further increased this complexity, accelerating the need to rethink health care delivery modes and move beyond traditional placebased models. From the service ecosystem perspective, eHealth is actually inherently reconfiguring itself because it is a dynamic and potentially self-adjusting service for service exchange. At the same time, value creation through resource integration affects the intrinsic nature of the system and, in turn, determines a change in the context for future value creation processes (Brodie et al., 2021). While the emergence of the service ecosystem, such as natural ecosystems, is beyond the complete control of any individual actor (Chandler et al., 2019), its evolution may be influenced at least partially by the actors' intended activities and practices (Vink et al., 2021; Mele et al., 2018). This process implies the reconfiguration of institutions and institutional arrangements (i.e. rules to coordinate activities among actors and support for coordination) by defining the context in which they perceive the potential embedded in resources. In this sense, the concept of "resourceness" aimed at understanding how potential resources become realised is particularly thought-provoking with regard to eHealth today. According to Koskela-Huotari and Vargo (2016, p. 164), resourceness is "the ability of potential resources to facilitate the accomplishment of something desirable". It is determined by the availability of other complementary and inhibiting potential resources, including the actors' ability to integrate and apply these resources.

An environment with different values, norms or principles would be more complex to manage, and it would be difficult to respond to external changes in it in a timely and flexible manner (Finsterwalder and Kuppelwieser, 2020). An example of an institution with a significant impact on the eHealth system is 
language, which enables communication and interaction between heterogeneous actors (EC, 2012). An equally important role in this service ecosystem is played by ICT, which facilitates and enhances interaction opportunities, overcoming the space and time boundaries between actors. Thus, the evolution of eHealth due to the COVID-19 pandemic "is part of an institutionalisation process in which rules are developed and shared and become a vital coordination mechanism" (Lusch et al., 2016, p. 2960). This institutionalisation process can be depicted in terms of institutional work that is "the purposive action of actors aimed at creating, maintaining and disrupting institutions" (Lawrence and Suddaby, 2006, p. 217) both for those actors who support the change and for those who resist it. The coordination mechanisms help purposefully support new practices in resource integration for mutual value co-creation (Edvardsson et al., 2014), to shape change in the service ecosystem especially during and after a crisis (Brodie et al., 2021).

\section{eHealth, cardiovascular disease and COVID-19}

The health-care scenario has changed rapidly worldwide during the COVID-19 pandemic because of the rapid reorganisation of hospitals and the increased burden on the emergency system due to the highly contagious nature of the disease. This evolution occurred primarily for COVID-19 patients, while other patients, particularly those with chronic diseases whose therapies and treatments require different services and multiple interfaces (Jefferies et al., 2019), have been largely neglected.

Patients with chronic medical conditions (CMCs) require regular access to health-care professionals and long-term treatments. A survey conducted from March to April 2020 by Carenity, a social platform that gathers more than 400,000 patients with chronic diseases and caregivers worldwide, and Alira Health (Carenity and Alira Health, 2020) provided thought-provoking data. For example, $42 \%$ of the patient respondents had cancelled or rescheduled a consultation or surgical intervention, $40 \%$ reported consulting their doctor less often than usual, $9 \%$ had stopped and/or interrupted their background treatment and $10 \%$ reported difficulties in purchasing their prescribed medications from a pharmacy. Other studies support these findings and add that less than $50 \%$ of the European CMC patients were satisfied with the information they received concerning their chronic conditions (Halioua et al., 2020). These data show a substantial risk of therapeutic discontinuity for patients requiring regular care and treatment, and the danger that they could become collateral victims of COVID-19.

According to data from the WHO (2020), among all chronic diseases, cardiovascular diseases are the leading cause of death globally, claiming an estimated 17.9 million lives each year and accounting for approximately $31 \%$ of all deaths worldwide. Four out of five cardiovascular-disease deaths occur in people under 70 years of age, due to heart attacks and strokes, and a third of these deaths occur prematurely.

The Italian Cardiology Society has stated that the COVID-19 pandemic has had a devastating impact on cardiovascular disease. The increase in mortality that has been observed during the pandemic is also due to increased deaths from cardiovascular causes. This phenomenon can be explained both by the direct effect of severe acute respiratory syndrome coronavirus 2 (the virus causing COVID-19) at the cardiovascular system level and by an indirect result of COVID-19 on patients suffering from acute and chronic cardiovascular disease.

Given the aforementioned setting, it is necessary to reconsider the service health-care ecosystem and how eHealth can be used as a long-term strategy for managing people with chronic diseases while bearing in mind that the adoption of digital health was a challenge in Italy, as elsewhere, before the pandemic (Petracca et al., 2020). Overall, reducing the exposure to risk factors, controlling them and providing timely and effective treatment services may prevent many deaths from this disease.

As of 2018, each of the 20 regions in Italy had implemented national telemedicine facilities according to specific guidelines, but this was only the primary stage of telemedicine implementation and involved very few patients (Diamond, 2020). However, as the pandemic has boosted the use of digital technologies to enable social distancing, the actors at different levels of the health-care service ecosystem are moving towards transforming the crisis into an excellent opportunity to rethink the organisational and relational models of care based on these technologies.

Digital health tools provide opportunities to reshape the health-care ecosystem by adopting digital health records and mobile apps and delivering a better quality of care at a more sustainable cost (Sust et al., 2020). Over the past 20 years, changes to the traditional structures and consequently to service ecosystems due to digital technologies have occurred. This evolution supported the introduction of new ways of integrating resources and the redefinition of actors' roles to enable better-quality care (Tuzii, 2017) and to improve healthcare services and individuals' and society's well-being. The eHealth service ecosystem is evolving particularly during the current pandemic, providing an opportunity for patients to receive care at home, in real time, and to interact with health care providers without going to hospitals, which many consider high-risk places for infection (Peltier et al., 2020; Shah et al., 2018). In this situation, the actors' interactions and integration have to be managed, considering the impact they may have at the different levels and on the existing practices and the obstacles that may occur on the go. Although remote monitoring of electronic cardiovascular devices, such as through defibrillators and cardiac resynchronisation systems implanted in patients with severe arrhythmias or heart failure, already existed even before the pandemic, its use has been implemented more effectively during the current pandemic. In this period, social distance has become a critical factor, and as such, the use of digital devices to treat chronic cardiovascular diseases has been fundamental in reducing care fragmentation and providing continuity of care (Lakkireddy et al., 2020; Melchiorre et al., 2018). Information concerning both the state of the device and the patient's clinical condition moves periodically through a secure and protected system from the patient's home to digital platforms constantly reviewed by technicians, cardiologists and clinicians in the hospital. These virtual platforms involve multiple players and promote patients' well-being. They provide the actors with tools to self-manage and increase their quality of life (Melchiorre et al., 2018), creating value through careful design and management (Ehret and Wirtz, 2018). The evolution of the eHealth service 
ecosystem, which has technological components, also provides human-machine interactions (Leone et al., 2021; Paschen et al., 2019). For example, AI customer-centric solutions may determine high-quality service innovation that can generate highquality care and improve the personalised chronic-disease patient journey (Leone et al., 2021; Følstad and Kvale, 2018).

From the aforementioned considerations, several research questions have emerged. Our study, in particular, focused on the following research questions:

RQ1. How has eHealth evolved during the pandemic particularly with regard to the treatment of patients with chronic cardiovascular diseases?

RQ2. How have the various actors interacted with one another and put in place different resources?

RQ3. What practices have been developed by the heterogeneous actors at different levels of the eHealth service ecosystem?

RQ4. How has the evolution of eHealth affected the different levels of the service ecosystem?

\section{Methodology}

\section{Research design}

To attain the aim of this study, we chose to use a qualitative method that matches the complexity of the issue addressed. The alternation between empirics and a diverse theoretical framework is helpful in creating new and additional insights (Yin, 2009; Orton, 1997). Furthermore, qualitative research aims at studying what is happening in various situations, giving such situations a holistic description and a contextual explanation (Ichikawa, 2017; Pettigrew, 2012). We investigated the Italian eHealth service ecosystem, focussing on the dynamics related to the actor engagement and resource integration processes because Italy was one of the countries earliest and most severely hit by COVID-19 and it has one of the highest COVID-19 death rates in the whole world. The Italian National Health System (INHS) provides universal access to care. Due to a decentralisation policy, the different regions in Italy, through local health organisations, organise and deliver primary, secondary, tertiary and preventive health-care services (Petracca et al., 2020). There are about 240,000 heart attack victims in Italy per year; cardiovascular diseases are the cause of $44 \%$ of all deaths, and those who survive a heart attack become chronic-disease patients. In Italy, about 7.5 million people suffer from cardiovascular disease, and during the current pandemic, a more than $50 \%$ reduction in hospitalisation rate for heart attacks has been registered. The rate of hospitalisation for heart failure, heart rhythm abnormalities and dysfunction of pacemakers and defibrillators is down by about a third.

The research reliability is based on a protocol that identifies the scheduling, procedures, recording and follow-up of the interviews.

\section{Data collection}

The study was conducted in a real context through 44 face-toface semi-structured interviews of heterogeneous Italian key informants from different levels of the eHealth service ecosystem, via Microsoft Teams. The interviews were carried out within the period from June 2020 to January 2021 (Table 1). The informants were selected assuming that information is best generated by those who know the phenomenon and are involved in digital health care. The heterogeneity of the interviews was designed to obtain a rich, multi-sided perspective of the three levels of the service ecosystem, and to generate a context-specific understanding of the phenomenon.

The interviews lasted $2 \mathrm{~h}$ on average, were carried out by the two researchers and generated 672 pages of single-spaced transcribed text. An interview protocol, with questions based on the literature, was developed to gather data about the nature and characteristics of the different actors involved in the Italian eHealth service ecosystem and their evolution, focusing on what had happened during the pandemic so far in terms of the resource integration and value co-creation mechanisms. The interviews also focussed on the future development of the eHealth service ecosystem. The questions were made semi-structured so that the interviewees could answer them as completely as possible. The interviews were recorded and transcribed to obtain as much data as possible from them. The discussions were informal and were facilitated with supporting questions and comments by the researchers.

\section{Data analysis}

This study adopted an abductive approach, which enabled a process where the theoretical framework and the data analysis evolved simultaneously. The research process was nonlinear and constantly matched reality and theory. The two researchers went back and forth between the theory and the data, modifying the theoretical framework with empirical findings derived from the semi-structured interviews. This new framework is a valuable guide to the process of data analysis for researchers (Dubois and Gadde, 2002).

The semi-structured interviews were recorded, transcribed and analysed through a coding process, and the content analysis (Neuman, 1997) by the two researchers was also part of the coding and interpretation process. The individual interviews were constantly compared with the others to develop consistent themes and findings and to consider other perspectives or different and new information (Spiggle, 2003). The differences between the two researchers' interpretations of the data obtained were then discussed (Beeler, et al., 2017) by the two researchers, and the final interpretation was submitted to the key informants (i.e. representatives of internal and external stakeholders) for a final evaluation. The comments and observations made during the coding processes provided a multi-level analysis. After data reduction and classification, the researchers sorted the codes into two main themes (i.e. drivers and inhibitors) based on how the different codes were related to one another (Gioia et al., 2013; Hsieh and Shannon, 2005). Six key issues emerged: actor role empowerment, actor-network engagement and resource reconfiguration as drivers, and inter- and intra-actor misalignment, resource myopia and platformisation gap as inhibitors.

\section{The evolution of the eHealth service ecosystem: a conceptual framework}

The pandemic has impacted the different layers of the eHealth service ecosystem, namely the macro, meso and micro levels, 
Table 1 Study interviews

\begin{tabular}{|c|c|c|}
\hline Role & No. of interviews & Pages of transcript \\
\hline Policymakers & 2 & 40 \\
\hline Patients & 5 & 67 \\
\hline Clinicians & 3 & 43 \\
\hline Caregivers & 3 & 41 \\
\hline Nurses & 2 & 38 \\
\hline Service providers & 2 & 43 \\
\hline Family doctors & 3 & 58 \\
\hline Technicians & 3 & 53 \\
\hline Cardiologists & 3 & 51 \\
\hline Information providers & 4 & 57 \\
\hline Technology providers & 3 & 46 \\
\hline Health tech start-up entrepreneurs & 4 & 62 \\
\hline Biomedical engineers & 2 & 26 \\
\hline Computer engineers & 3 & 37 \\
\hline Volunteers of NPO Associations & 2 & 10 \\
\hline
\end{tabular}

with effects on an already-underway evolution. It is noteworthy that although this evolution started more than 20 years ago, it remained in a sort of an introductory stage until very recently. Almost 10 years have passed since the publication by the EC of the 2012-2020 “eHealth" Action Plan (EC, 2012), which urged the EC member states to accelerate their actions aimed at exploiting the potential of eHealth. In reality, this is not yet a fait accompli, at least in Italy. It took the COVID-19 outbreak to make us talk meaningfully about the importance of eHealth and to see some concrete action, especially for the management of chronic diseases.

It was found in this study that the evolution of the eHealth service ecosystem had been accelerated during the current pandemic, induced by changes in the types of actors involved, in the shared worldviews regarding models of care and in the resource integration processes resulting from technology development and diffusion (Kraus et al., 2021). What is quite clear is that eHealth means more than the technological development of health care. It involves complex interactions in a multi-stakeholder context, characterised by a multi-faceted decision-making process (Brodie et al., 2021).

The changes observed affect all the levels of the service ecosystem, although the meso level was significantly more involved in the process, as we shall see in greater detail later in the paper. As happens in the case of every evolutionary process and as the most recent literature points out (Brodie et al., 2021; McColl-Kennedy et al., 2020), we can observe both the propulsive factors that have driven the process of evolution and that will continue to drive it in the future, and the factors that restrain the development, mainly related to the tensions brought about by the different actors' perspectives on eHealth and the resistance or inability to integrate resources to co-create value. The pandemic has also created the conditions for new players to enter the service ecosystem, seizing the emerging opportunities and intervening in the eHealth dynamics. In particular, we have observed a redefinition of the roles of some of the ecosystem's actors, which have gained a different relevance in orienting and supporting eHealth development. These actors and the implications for the empowerment of their roles represent one of the main drivers of change. The entry of these new players and their progressive involvement have also led to the creation of new networks of players at various levels of the service ecosystem. This process has led to the promotion of innovative projects to create the best conditions to support the spread of eHealth across the different layers. Therefore, actor engagement has shifted from the micro level's typically dyadic relationship to the multi-faceted dimension of the meso level. It is precisely at this level that we observed the most dynamic forces driving the evolution of the eHealth service ecosystem. This change has been reflected in the types of resources that the actors have started to integrate and in the adoption of practices that have led to their reconfiguration in the value creation process. In contrast to the drivers that sustain the evolution of the service ecosystem, the study also revealed several factors that hinder eHealth's diffusion and integration into the broader health-care system. These factors relate in part to intangible dimensions, such as the perceptions, attitudes, skills and shared visions of the various players in the service ecosystem, and in part to more tangible dimensions, such as the misalignment of technological platforms, which integrate a large amount of data from various sources. A further element challenging the service ecosystem evolution is the myopic perspective adopted towards the re-use of some resources: the re-use of processes for monitoring and caring adopted for COVID-19 patients via electronic devices to improve chronic-disease patients' management in hospitals and clinics.

The consideration of all these factors led us to the conceptual framework presented in Figure 1.

\section{Drivers}

In this study, three drivers emerged as key issues in the evolutionary process of the eHealth service ecosystem accelerated by COVID-19: actor role empowerment, actornetwork engagement and resource reconfiguration.

\section{Actor role empowerment}

The interviews that were conducted showed that among the central relationships in the eHealth service ecosystem are those among the family doctor, the cardiologist and the patient (McColl-Kennedy et al., 2017; Black and Gallan, 2015). The 
Figure 1 Drivers and inhibitors in the evolution process of the eHealth service ecosystem

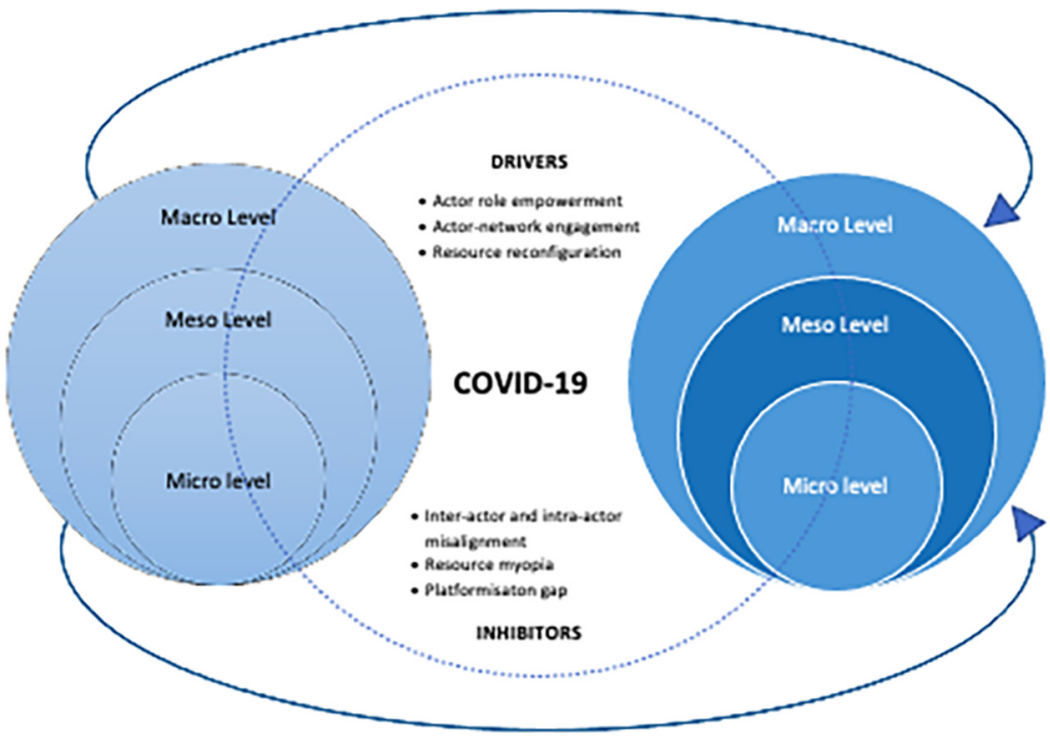

role of the specialist in promoting eHealth and coordinating the other actors is becoming increasingly pivotal. The cardiologist is becoming more and better informed about technologies and digital tools than before the COVID-19 pandemic:

More change-conscious clinicians are pushing for home monitoring of patients with different technological tools. They are much better informed than before, are more familiar with technological tools, are able to choose between the proposals of the various competitors and are also able to explain to their patients how to use these devices. (Technology provider)

The role of the cardiologist is also important because he/she is often the sponsor of the adoption of eHealth solutions; data show that telehealth, telemedicine and the use of eHealth tools are implemented only when there is an internal sponsor:

If a telemedicine project is imposed from above, it will certainly not succeed. The existence of an internal hospital sponsor almost always ensures the success of the project. (Technician)

Patients are now actively responding to technological options more than in the past; many patients with a cardiovascular disease, regardless of age, have adapted to the use of technological devices that can remotely monitor their parameters and health status. From the interviews, it is clear that it has been essential for patients, even psychologically, to feel that they are constantly monitored during the pandemic and that patients have realised that they can be continuously treated at home even in complex situations.

In the evolutionary eHealth service ecosystem, the role of caregivers and relatives has also been improved. They have learned how to use new technological devices and how to deal with remote treatments:

I also learned to use technological devices. I did not find it easy to manage this situation at the beginning. Only through teamwork with the family doctor, the specialist and the reference nurse was I able to eventually understand how to manage not only the therapy but also the monitoring of some parameters at home. (Caregiver)

Furthermore, data revealed that biomedical engineers have assumed a more empowered role. From offering simple technical support, engineers now provide unforeseen technological skills to clinicians, doctors and nurses in this new context:
The biomedical engineer started to be part of the hospital staff, playing the role of a bridge between the clinicians and the ICT manager [...] In this way, he manages to integrate the technological skills that the clinician does not have. (Biomedical engineer)

At a different level, the role of system integrators, who provide public and private health operators with integrated telemedicine solutions, has been enhanced during the COVID-19 pandemic. The integrated telemedicine solutions provided by system integrators aim to simplify and integrate the acquisition of clinical data from chronic-disease patients and to improve the treatment and management of patients with cardiovascular diseases remotely.

Actor-network engagement

Previous studies in the field of chronic-disease management have underlined the importance of collaborative relationships not only at the micro level (McColl-Kennedy et al., 2020) but also at the meso level among the service providers, hospitals, health tech start-ups and others:

Our focus is on the product. Product performance is of interest to all clinicians today. A network logic allows even small companies to bring their know-how to bear and to integrate this with those of the players already in the network. (Health tech start-up entrepreneur)

The COVID-19 pandemic has enhanced the engagement of multiple actors from a service ecosystem perspective. Creating a value proposition for cardiovascular-disease patients requires new interactions beyond the traditional dyadic relationship. These interactions involve different actors generating new practices and adapting existing ones (Brodie et al., 2019; Edvardsson et al., 2014; Geels and Schot, 2007):

Our challenge at the moment is to create a common value proposition also involving the other actors of the system, which serves the patient with chronic cardiovascular disease. (Technology provider)

The development of technology and the diffusion of technological devices and tools in the eHealth service ecosystem imply the creation of new relations and networks that overcome the different layers. The COVID-19 pandemic has impacted the eHealth service ecosystem by building meaningful interactions within and among the micro, meso and 
macro levels. This process of change requires overcoming barriers and tensions and creating convergent logics among the different actors (Jaakkola et al., 2019; Aarikka-Stenroos et al., 2017; Öberg et al., 2016):

It is important to share a project with all the players in the system, including, or may I say especially, with the cardiologist and the interventional cardiac surgery departments. If the project is shared, it will be possible to overcome the problems arising from lack of patient compliance. (Clinician)

The regions in Italy play a fundamental role in the reshaping of actors' roles and engagement. Given their position in the INHS, the regions can increasingly become key actors in this ecosystem and can improve the creation of new interactions among the actors at the different levels of the service ecosystem.

As with the regions, at the meso level, our interviews also showed the importance of non-profit associations, which have implemented innovative ways of caring for patients, overcoming social distance to lessen patients' loneliness and fear of disease infection and thereby improving their adherence to care.

\section{Resource reconfiguration}

During the first phase of the COVID-19 pandemic, there were only limited changes in the implementation of telemedicine tools. However, during the second phase, it has become clear how useful these tools can be for the remote monitoring of cardiovascular-disease patients.

Resource integration has generated cooperation, collaboration and mutual outcomes for all the actors in the ecosystem (Edvardsson et al., 2014) and has boosted the process of rebuilding the original resource configuration:

The pandemic has reshaped the relationship of patients with the healthcare system, especially for patients with a chronic cardiovascular disease. The ability to manage a patient's condition remotely has been proven to be a major asset. (Cardiologist)

The dynamic creation of new types of relationships particularly during the second phase of the pandemic has developed the eHealth service ecosystem, and resource reconfiguration has enhanced the design of new solutions and outcomes:

The use of the [smart] T-shirt to monitor patients and to gather data faster had a positive impact. The patient feels monitored constantly and does not feel abandoned even if he/she does not go to the hospital. (Nurse)

Resource reconfiguration provides an improved and integrated eHealth service ecosystem due to multi-level interactions and the creation of synergies (Meynhardt et al., 2016). Data have also shown, however, that a digital environment is complicated to manage. Resource reconfiguration also involves new and different ways of integrating operant resources to create virtual platforms. Remote patient monitoring is a valuable way to monitor and manage patients' cardiovascular disease through AI algorithms and risk evaluation (Leone et al., 2021). Integration with telemedicine tools enables actors' engagement. In patient monitoring, particularly in the second phase of the epidemic, a key role has been played by the actors with a presence in the local community:

Pharmacies have been proactive in monitoring patients with a chronic cardiovascular disease, and above all have played a key role in the hospitalcommunity relationship. Very often, they became a point of reference for patients who, instead of going to the emergency room went to the pharmacies, where they knew there were some devices useful for monitoring their parameters. (Information provider)

\section{Inhibitors}

Aside from the drivers of the evolution of the eHealth service ecosystem, three main inhibitors also emerged from the study: inter- and intra-actor misalignment, resource myopia and platformisation gap.

\section{Inter-and intra-actor misalignment}

The actors who were interviewed complained about the lack of mutual understanding and common worldviews. The involvement of new actors in the ecosystem brings to light the difficulty of sharing a common vision for the actors operating at the same or different ecosystem levels. Sometimes, the languages used by the actors in this eHealth ecosystem are different; at other times, the problem is more profound because the actors' perspectives are different:

Sometimes the problem is not only the language but also the vision of the project, which is completely different from one actor to another. The actors seem to look at the same problem from completely different perspectives, and this then generates problems in formulating effective responses to patients. If there were a common vision, it would be easier to understand which hospital visits are really necessary and then to define an integrated home care programme. (Family doctor)

There is a lack of central coordination. Many actors have associated telemedicine with a purely ICT-based service. There is a lack of a common language between the actors, which does not facilitate connections and makes it difficult to carry out shared projects. (Computer engineer)

Lack of coordination and a shared worldview has inhibited and continues to inhibit the development of the eHealth service ecosystem during the current pandemic. From the interviews, it is clear that new institutional arrangements have not yet been developed, such as with regard to what is happening among the different hospital departments. When misalignments of worldviews occur at different levels, they can result in conflicts and tensions that will have a negative effect on value co-creation:

We need to work on the computer literacy of all the actors, old and new, involved in these new workflows [...] This is also useful for the management of home care, for making it as widespread as possible throughout the community and for speeding up certain dynamics that are still very slow today. (Technology provider)

\section{Resource myopia}

Although the use of technological tools has increased during the second phase of COVID-19, there are only few diagnosisrelated groups (DRGs) for implementing eHealth solutions in the regions. While in December 2020 the Ministry of Health issued an official document introducing eHealth as an essential level of care, there is currently a lack of implementation at the regional level:

Compared to the first phase, there is definitely more focus on eHealth today; however, it is almost always all about COVID-19, without taking into account that the tools I am using today will also serve me in the future for the management of patients with chronic cardiovascular diseases. (Cardiologist)

The interviews revealed a fundamental issue: there is a shortsighted use of technological resources. Even hospitals that have purchased technological tools have not yet understood the full potential of such tools. Many devices that are useful for the treatment of COVID-19 patients can also be used to manage patients with a cardiovascular disease at home, thus enabling them to avoid hospitalisation and reducing the risk of virus transmission: 
Some hospitals have purchased technology products and services for the remote monitoring of COVID-19 patients, but they are not using these technologies to manage patients with a chronic cardiovascular disease. (Clinician)

In this transition enabled by the COVID-19 pandemic, the eHealth service ecosystem does not seem to be as permeable or resilient as it can be. This situation is confirmed by a shortsighted view of AI, which is still undervalued:

We are not yet investing in AI [...] we have yet to recognise its potential for prioritising care for the patients we are currently treating at home given their chronically ill conditions. (Computer engineer)

\section{Platformisation gap}

According to the interviews, the lack of a "virtual context", in which actors are coordinated and have the same worldviews and the same visions, is clearly an inhibitor for the evolution of the eHealth service ecosystem. This effect manifests at different levels. One level relates to data gathering, analysis, transmission and privacy. Another level concerns the lack of a structured network essential for creating a widespread intervention on the ground with the engagement of actors at all levels, from the INHS to the regions to the family doctors:

Coordination is also lacking in this second phase of the pandemic. Many people continue to associate telemedicine with a purely ICT service, without taking into account that it also consists of a virtual platform between the different actors, which is a real enabling factor. (Computer engineer)

The absence of coordination makes it very difficult to create a value proposition for patients with a chronic cardiovascular disease and also to create ad hoc solutions for their treatment based on renewed processes and practices (Russo Spena and Mele, 2019):

Telemedicine alone cannot be the solution for chronic-disease patients: Who follows up the patients remotely? Who pays? The pandemic has also highlighted the limitations of the existing healthcare model. (Information provider)

The presence of new actors in the eHealth service ecosystem helps avoid problems related to the remote monitoring of patients. Still, there is no effective coordination among the different players. The absence of a virtual platform where actors can interact with one another and create connections among themselves inhibits the sharing of best practices and data:

Not all regions behave in the same way and invest or have invested in telemedicine to the same extent. There is no single regional tool that all hospitals should be equipped with [...] the existence of different technologies does not allow for the transmission of data. (Technician)

More extensive coordination and collaboration can effectively address the aforementioned platformisation gap. This may imply integrating and reconfiguring resources at all eHealth service ecosystems to work in a more robust and transformational way to co-create value.

Table 2 summarises the main findings of the study.

\section{Discussion}

During the COVID-19 pandemic so far, the health-care service ecosystem has shown vulnerability especially in managing patients with chronic diseases. According to the main results of this study, eHealth may be a potential solution to supporting the future evolution of the entire service ecosystem by addressing key contentious issues.
The mega-disruptions triggered by the pandemic have improved the interactions and resource integration between the actors at different levels of the eHealth service ecosystem. However, the analysis revealed some factors as being of particular interest because of their ability to support or constrain the ongoing process of evolution.

The conceptual framework proposed in this paper (Figure 1) helps in understanding the dynamics of the evolution of the eHealth service ecosystem, focussing on opportunities and criticalities. During the COVID-19 pandemic, the evolution of the eHealth service ecosystem has accelerated due to the improvement of technology. This evolution involves more complex interactions, which occur in a context where actors intervene for the first time or assume new roles in a fragmented decision-making process (Brodie et al., 2021) to reduce fragmentation and provide continuity of care (Melchiorre et al., 2018) for patients with chronic cardiovascular diseases. In this digitalised context, the process of value co-creation concerns not only the focal actors, such as the doctors and patients but also the other actors who intervene at the various levels of the eHealth service ecosystem (Gallan et al., 2019; Nakata et al., 2019).

While the role of the specialist in promoting eHealth and in coordinating with the other actors in the service ecosystem has increased (McColl-Kennedy et al., 2017), new protagonists emerge, intervening in the complex system of relationships and extending the boundaries of possible interactions among the heterogeneous system actors. This improvement of multi-actor engagement in eHealth as a result of the COVID-19 pandemic creates ongoing processes and projects that continually build, challenge and transform the existing ecosystem (Kraus et al., 2021; McColl-Kennedy et al., 2020). It adapts to the new context generated by the COVID-19 pandemic through the knowledge, skills and know-how shared by the actors (Kraus et al., 2021).

In this new configuration, technological and digital tools may be considered operant resources (Sklyar et al., 2019); actors at different levels of the ecosystem reconfigure resource integration and enable coordination and knowledge sharing through the use of operand resources such as raw data derived from devices.

The adoption of digital records, mobile apps, smart T-shirts, smart watches and the like provides an opportunity to reconfigure the health-care service ecosystem to deliver remote care for chronic-disease patients at a more sustainable cost (Sust et al., 2020). Data concerning device usage and patients' conditions are starting to be integrated into digital platforms thanks to the collaboration among the different actors in the service ecosystem. Moreover, high-quality health-care solutions can include AI, which can improve the chronicdisease patients' journey (Leone et al., 2021; Følstad and Kvale, 2018).

The introduction and use of digital technologies in the eHealth ecosystem have created a new path of resource integration, redefinition of the actors' roles and new interactions at the micro, meso and macro levels. In contrast, however, the evolution of the eHealth service ecosystem boosted by the COVID-19 pandemic has also been inhibited by a number of factors, such as inter- and intra-actor misalignment, the myopic use of resources and the existence of a platformisation gap. The coordination issue is 
Quotes

Key issues

If a telemedicine project is imposed from above, it will certainly not succeed. The existence of

Actor role themes

an internal hospital sponsor almost always ensures the success of the project (Technician) empowerment DRIVERS

The caregiver plays an increasingly important role, he/she should be able to manage technological devices and e-therapies and to monitor parameters at home (Cardiologist) I am a rather elderly patient, I didn't really know what the term telemedicine meant, then during the Covid I had to learn how to monitor my parameters at home and relate in a different way to my cardiologist, avoiding going to the hospital (Patient) Today, more than ever, the role of the regions is becoming more fundamental as key players in creating new interactions and reconfiguring existing relationships (Policy maker) The relationship is no longer just between the cardiologist and the patient, the logic of the dyadic relationship has been overcome: co-creating value for and with the patient today also means proposing alternative solutions. The non-profit association I volunteer for, for example, which used to help patients by wandering the hospital wards, has now implemented new services to stay close to patients and overcome the physical distance imposed by the pandemic (Volunteer, retired nurse)

Our focus is on the product. Product performance is of interest to all clinicians today. A network logic allows even small companies to bring their know-how to bear and to integrate this with those of the players already in the network (Health tech start-up entrepreneur) The transition from the physical to the digital environment is not easy to manage, a different and new integration of resources is needed, useful to co-create value for the patient and for society as a whole (Technology provider) The pandemic has reshaped the relationship of patients with the health-care system, especially for patients with a chronic cardiovascular disease. The ability to manage a patient's condition remotely has been proven to be a major asset (Cardiologist)

I believe in this moment it is necessary to share resources, activate a real process of reconfiguration and understand how to fit the various pieces of the puzzle, bearing in mind the dynamism of the situation and the speed with which everything is constantly changing (Family doctor)

There is a lack of central coordination. Many actors have associated telemedicine with a purely ICT-based service. There is a lack of a common language between the actors, which does not facilitate connections and makes it difficult to carry out shared projects (Computer engineer)

We talk more and more often about interventions on the territory for chronic patients, but the real problem is that there is a lack of real coordination between the actors involved, which is useful for value co-creation, particularly in this period of pandemic (Cardiologist) We need to work on the computer literacy of all the actors, old and new, involved in these new workflows ... this is also useful for the management of home care, to be as widespread as possible throughout the community and to speed up certain dynamics that are still very slow today (Technology provider)

We are not yet investing in Al ... we have yet to recognise its potential for prioritising care for the patients we are currently treating at home given their chronically ill conditions (Computer engineer)

In the hospital we are very focused on what is going on right now, we should start using some technologies also for remote monitoring of chronic patients with cardiovascular diseases (Nurse)

A virtual platform would also be useful for the management and analysis of data transmitted by patients who are remotely monitored. This would allow us to share information faster and manage critical events more quickly (Computer engineer)

I think that today there is a lack of a real widespread network operating on the territory ... We need to create a widespread network involving all the players in the system, from the regions to pharmacies, family doctors ... (Caregiver)

Not all regions behave in the same way and invest or have invested in telemedicine to the same extent. There is no single regional tool that all hospitals should be equipped with ... the existence of different technologies does not allow for the transmission of data (Technician)

Inter-actor and intraactor misalignment

Resource reconfiguration

Resource myopia 
closely related to the lack of institutional arrangements providing rules and shared languages that can help the actors make sense of and help build the pillars of the eHealth service ecosystem (McColl-Kennedy et al., 2020; Cheung and McColl-Kennedy, 2015; Edvardsson et al., 2014). These deficiencies delay the construction of the complex context in which new and existing actors can interact with one another and co-exist. Furthermore, this revised eHealth service ecosystem requires transformational capabilities (Brodie et al., 2021) to prevent problems related to the myopic use of resources and the absence of institutionalised processes. For example, technology providers contribute to the service ecosystem evolution through the creation of value from data, and this provides new personalised services for the remote monitoring of chronic-disease patients. The large amounts of data generated are also beneficial for predictive analysis, whose results need to be shared with the other actors in the service ecosystem. However, it is essential to consider privacy policies and the need to balance health protection and privacy (Laurenza et al., 2018). In the reconfiguration of the eHealth service ecosystem, it is necessary to consider a multi-level strategy that the actors at the micro, meso and macro levels can use to acquire, protect and analyse data through a progressive institutionalisation of norms and rules appropriately developed with the aim of protecting patients' privacy but concurrently ensuring effective personalised cures.

Therefore, a service ecosystem perspective can inform the conceptual building blocks of participatory service design in a way that supports a better understanding of the actors' efforts to influence intentional, long-term change in digital service systems (Vink et al., 2021). Resource integration happens when institutions, as in this eHealth service ecosystem, coordinate the reconfiguration (Edvardsson et al., 2014). Data clearly show that partnerships at all levels can boost skills and activities in a certain period and in a context in which new collaborations continuously modify resource combinations (Leach et al., 2020; McFarland, 2019). The meso level is gaining a pivotal role in this process, representing the privileged locus of interaction among service providers, hospitals, health tech start-ups, patients' associations and the like, because the process of change requires overcoming barriers and tensions and the creation of convergent logics not only among the different actors (Jaakkola et al., 2019) but also among the different levels.

\section{Conclusions and implications}

The COVID-19 pandemic has boosted the evolution of the eHealth service ecosystem; the use of digital tools creates opportunities to reconfigure the service ecosystem and to offer high-quality care to patients with chronic cardiovascular diseases. In this ecosystem, mediated by the complex pandemic situation, new and existing players recombine and integrate resources in new and different ways, co-creating transformational value supporting the evolution of the broader health-care ecosystem.

At the theoretical level, our paper makes an important contribution: paving the way for the application of a service ecosystem perspective and of the S-D logic in the eHealth sector focused on the management of patients with chronic cardiovascular diseases during the COVID-19 pandemic.
The framework presented in Figure 1 provides a thoughtprovoking illustration of how the eHealth service ecosystem is evolving and of the main drivers and inhibitors of the evolutionary process. It highlights the enhanced roles of actors that are becoming increasingly pivotal in the diffusion of eHealth practices, such as specialists, caregivers, ICT managers and technology providers. Interestingly, the study results show that the meso level assumes a particular function in supporting the evolution by creating new networks of heterogeneous actors endeavouring to come up with new projects aimed at contributing to the institutional work related to the service ecosystem development. This institutional work affects the types of resources integrated among the actors, the practices of integration, the norms and rules governing these mechanisms and the sharing of common visions by the same actors.

As in many evolutionary processes, however, constraints emerge along the way. In particular, the factors inhibiting the diffusion and integration of eHealth are related both to intangible and tangible elements. In the first group, we observed how the heterogeneous actors express perceptions, attitudes, skills and worldviews that need to be aligned. Regarding more tangible factors, the different technological platforms and standards already existing in the service ecosystem help delay the process of data integration, which appears to be one of the crucial factors related to the widespread adoption of eHealth. Myopia, characterising the way of considering and consequently using resources already available but employed for other aims, such as for the remote monitoring of COVID-19 patients, represents another important piece of the puzzle emerging from the study.

The paper also shows several implications for practice. For dealing with the different actors at the different levels of the eHealth service ecosystem, the institutionalisation of the digital integration processes to create a personalised patient journey by sharing worldviews and a common language seems to be an unavoidable starting point.

At the policy level, policymakers can consider the evidence that emerged from the study to support the adoption of the state-region agreement issued in December 2020, in which telemedicine was introduced for the first time as one of the basic levels of care.

Policymakers are also called to improve territorial and community health care and to strengthen their coordination role to plan and manage the eHealth service ecosystem during and after the current COVID-19 pandemic. In this sense, particularly at the meso level, it is important for policymakers to consider the actual fragmentation of and the lack of uniformity among the different DRGs and to facilitate an agreement across the local communities.

Another key issue is the creation of technology standards that are useful for integrating and coordinating the different platforms and for reducing the platformisation gap highlighted in this paper.

To be able to offer remote high-quality care and quick solutions to chronic-disease patients, an urgent need to create a common valuable database containing data from different patients and sources that will be made available to all the interacting actors clearly emerged from the present study.

The large amount of data that can be collected through remote monitoring can in fact offer solutions for 
chronic-disease patients not only during the current pandemic but also in the future and can enable the study and analysis of effective future solutions for the prevention of chronic cardiovascular diseases and for immediate interventions for such.

Finally, to overcome the problems related to doctors' (particularly cardiologists') and nurses' lack of technology competencies and resulting resistance to eHealth, health-care organisations should invest in training and in incentive and motivation systems.

Future studies can also continue to investigate the evolution of the eHealth service ecosystem, focusing more on the role of institutions and on the integration of operand and operant resources. Furthermore, while the focus on only one country, such as Italy, can reflect a specific and partial view of the complex evolution of eHealth service ecosystems, it would be very interesting to embark on a comparative study of several European countries to map out the complex interconnections among the different eHealth service ecosystems and to create a framework for investigating the best practices and supporting the creation of an integrated eHealth system at the European level.

\section{References}

Aarikka-Stenroos, L., Jaakkola, E., Harrison, D. and MäkitaloKeinonen, T. (2017), "How to manage innovation processes in extensive networks: a longitudinal study", Industrial Marketing Management, Vol. 67, pp. 88-105.

Beeler, L., Zablah, A. and Johnston, W.J. (2017), "How critical events shape the evolution of sales organizations: a case study of a business-to-business services firm", fournal of Business Research, Vol. 74, pp. 66-76.

Belliger, A. and Krieger, D.J. (2018), "The digital transformation of healthcare", in North, K., Maier, R. and Haas, O. (Eds), Knowledge Management in Digital Change. Progress in IS, Springer, Cham, pp. 311-326.

Black, H.G. and Gallan, A.S. (2015), "Transformative service networks: cocreated value as well-being", The Service Industries fournal, Vol. 35 Nos 15/16, pp. 826-845.

Botti, A. and Monda, A. (2020), "Sustainable value cocreation and digital health: the case of Trentino eHealth ecosystem", Sustainability, Vol. 12 No. 13, p. 5263.

Brodie, R.J., Fehrer, J.A., Jaakkola, E. and Conduit, J. (2019), "Actor engagement in networks: defining the conceptual domain”, fournal of Service Research, Vol. 22 No. 2, pp. 173-188.

Brodie, R.J., Ranjan, K.R., Verreynne, M.L., Jiang, Y. and Previte, J. (2021), "Coronavirus crisis and health care: learning from a service ecosystem perspective", fournal of Service Theory and Practice, Vol. 31 No. 2, pp. 225-246.

Carenity and Alira Health (2020), available at: www. prnewswire.com/news-releases/covid-19-and-chronic-illnesseswill-chronic-patients-be-collateral-victims-of-the-pandemic301040472.html?tc=eml_cleartime (accessed February 2021).

Chandler, J.D., Danatzis, I., Wernicke, C., Akaka, M.A. and Reynolds, D. (2019), "How does innovation emerge in a service ecosystem?”, fournal of Service Research, Vol. 22 No. 1, pp. 75-89.

Cheung, L. and McColl-Kennedy, J.R. (2015), "Resource integration in liminal periods: transitioning to transformative service", Fournal of Services Marketing, Vol. 29 Nos 6/7, pp. 485-497.

Chi, N.C. and Demiris, G. (2015), "A systematic review of telehealth tools and interventions to support family caregivers", Fournal of Telemedicine and Telecare, Vol. 21 No. 1, pp. 37-44.

Cichosz, S.L., Johansen, M.D. and Hejlesen, O. (2016), "Toward big data analytics: review of predictive models in management of diabetes and its complications", fournal of Diabetes Science and Technology, Vol. 10 No. 1, pp. 27-34.

Corbett, J.A., Opladen, J.M. and Bisognano, J.D. (2020), "Telemedicine can revolutionize the treatment of chronic disease", International fournal of Cardiology Hypertension, Vol. 7, p. 100051.

Cormi, C., Chrusciel, J., Laplanche, D., Dramé, M. and Sanchez, S. (2020), "Telemedicine in nursing homes during the COVID-19 outbreak: a star is born (again)", Geriatrics $\mathcal{E}$ Gerontology International, pp. 1-2, doi: 10.1111/ggi.13934.

De Rosa, S., Spaccarotella, C., Basso, C., Calabrò, M.P., Curcio, A., Filardi, P.P., Mancone, M., Mercuro, G., Muscoli, S., Nodari, S. and Pedrinelli, R. (2020), "Reduction of hospitalizations for myocardial infarction in Italy in the COVID-19 era", European Heart Fournal, Vol. 41 No. 22, pp. 2083-2088.

Diamond, F. (2020), "Fight COVID-19 with telemedicine", Infection Control Today (2020), available at: www. infectioncontroltoday.com/view/fight-covid-19-telemedicine (accessed February 2021).

Dubois, A. and Gadde, L.E. (2002), "Systematic combining: an abductive approach to case research", fournal of Business Research, Vol. 55 No. 7, pp. 553-560.

Edvardsson, B., Kleinaltenkamp, M., Tronvoll, B., McHugh, P. and Windahl, C. (2014), "Institutional logics matter when coordinating resource integration", Marketing Theory, Vol. 14 No. 3, pp. 291-309.

Ehret, M. and Wirtz, J. (2018), "Ownership of co-creation assets: driving $\mathrm{B} 2 \mathrm{~B}$ value propositions in the service economy", fournal of Creating Value, Vol. 4 No. 1, pp. 42-60.

European Commission (2012), "European commission eHealth action plan 2012-2020. Innovative healthcare for the 21st century", available at: www.ehealthnews.eu/ download/publications (accessed February 2021).

Eysenbach, G. (2001), "What is e-health?", Fournal of Medical Internet Research, Vol. 3 No. 2, p. e20.

Farabi, H., Rezapour, A., Jahangiri, R., Jafari, A., Kemmak, A. R. and Nikjoo, S. (2020), "Economic evaluation of the utilization of telemedicine for patients with cardiovascular disease: a systematic review", Heart Failure Reviews, Vol. 25 No. 6, pp. 1063-1075.

Finsterwalder, J. and Kuppelwieser, V.G. (2020), "Equilibrating resources and challenges during crises: a framework for service ecosystem well-being", fournal of Service Management, Vol. 31 No. 6, pp. 1107-1129.

Følstad, A. and Kvale, K. (2018), "Customer journeys: a systematic literature review", fournal of Service Theory and Practice, Vol. 28 No. 2, pp. 196-227.

Ford, G., Compton, M., Millett, G. and Tzortzis, A. (2017), "The role of digital disruption in healthcare service innovation", in Pfannstiel, M. and Rasche, C. (Eds), Service Business Model Innovation in Healthcare and Hospital Management, Springer, Cham, pp. 57-70. 
Frow, P., McColl-Kennedy, J.R. and Payne, A. (2016), "Cocreation practices: their role in shaping a health care ecosystem", Industrial Marketing Management, Vol. 56, pp. 24-39.

Frow, P., McColl-Kennedy, J.R., Payne, A. and Govind, R. (2019), "Service ecosystem well-being: conceptualization and implications for theory and practice", European fournal of Marketing, Vol. 53 No. 12, pp. 2657-2691.

Gallan, A.S., McColl-Kennedy, J.R., Barakshina, T., Figueiredo, B., Jefferies, J.G., Gollnhofer, J., Hibbert, S., Luca, N., Roy, S., Spanjol, J. and Winklhofer, H. (2019), "Transforming community well-being through patients' lived experiences", Fournal of Business Research, Vol. 100, pp. 376-391.

Geels, F.W. and Schot, J. (2007), "Typology of sociotechnical transition pathways”, Research Policy, Vol. 36 No. 3, pp. 399-417.

Gioia, D.A., Corley, K.G. and Hamilton, A.L. (2013), "Seeking qualitative rigor in inductive research notes on the Gioia methodology", Organizational Research Methods, Vol. 16 No. 1, pp. 15-31.

Halioua, B., Zetlaoui, J., Astruc, A., Lévy-Heidmann, T., Testa, D. and Bombezin, A. (2020), "PMU85 IMPACT of the COVID-19 pandemic on patients affected by chronic diseases in Europe", Value in Health, Vol. 23, p. S617.

Hanlon, P., Daines, L., Campbell, C., McKinstry, B., Weller, D. and Pinnock, H. (2017), "Telehealth interventions to support self-management of long-term conditions: a systematic metareview of diabetes, heart failure, asthma, chronic obstructive pulmonary disease, and cancer", fournal of Medical Internet Research, Vol. 19 No. 5, p. e172.

Hsieh, H.F. and Shannon, S.E. (2005), "Three approaches to qualitative content analysis", Qualitative Health Research, Vol. 15 No. 9, pp. 1277-1288.

Ichikawa, J.J. (2017), Contextualising Knowledge: Epistemology and Semantics, Oxford University Press, Oxford.

Jaakkola, E., Aarikka-Stenroos, L. and Ritala, P. (2019), "Institutionalization process of service innovation: overcoming competing institutional logics in service ecosystems", in Maglio, P., Kieliszewski, C., Spohrer, J., Lyons, K., Patrício, L. and Sawatani, Y. (Eds), Handbook of Service Science, Service Science: Research and Innovations in the Service Economy, Springer, Cham, Vol. 2, pp. 497-516.

Jefferies, J.G., Bishop, S. and Hibbert, S. (2019), "Customer boundary work to navigate institutional arrangements around service interactions: exploring the case of telehealth", Fournal of Business Research, Vol. 105, pp. 420-433.

Kabadayi, S., O'Connor, G.E. and Tuzovic, S. (2020), "Viewpoint: the impact of coronavirus on service ecosystems as service mega-disruptions", fournal of Services Marketing, Vol. 34 No. 6, pp. 809-817.

Koskela-Huotari, K. and Vargo, S.L. (2016), "Institutions as resource context", Fournal of Service Theory and Practice, Vol. 26 No. 2, pp. 163-178.

Kraus, S., Schiavone, F., Pluzhnikova, A. and Invernizzi, A.C. (2021), "Digital transformation in healthcare: analyzing the current state-of-research", fournal of Business Research, Vol. 123, pp. 557-567.

Kuppelwieser, V.G. and Finsterwalder, J. (2016), "Transformative service research and service dominant logic: quo vaditis?", fournal of Retailing and Consumer Services, Vol. 28, pp. 91-98.
Lakkireddy, D.R., Chung, M.K., Deering, T.F., Gopinathannair, R., Albert, C.M., Epstein, L.M., Harding, C.V., Hurwitz, J.L., Jeffery, C.C., Krahn, A.D. and Kusumoto, F.M. (2020), "Guidance for rebooting electrophysiology through the COVID-19 pandemic from the heart rhythm society and the American heart association electrocardiography and arrhythmias committee of the council on clinical cardiology", Circulation: Arrhythmia and Electrophysiology, Vol. 13 No. 7, p. e008999.

Laurenza, E., Quintano, M., Schiavone, F. and Vrontis, D. (2018), "The effect of digital technologies adoption in healthcare industry: a case based analysis", Business Process Management Fournal, Vol. 24 No. 5, pp. 1124-1144.

Lawrence, T.B. and Suddaby, R. (2006), "Institutions and institutional work", in Clegg, S.R., Hardy, C., Lawrence, T. and Nord, W.R. (Eds), The Sage Handbook of Organization Studies, Sage, London, pp. 215-254.

Leach, M.P., Epler, R.T. and Wang, S. (2020), "Adapting sales influence tactics in the information intensive era", Fournal of Business $\mathcal{E}$ Industrial Marketing, Vol. 36 No. 8, pp. 1261-1272.

Leone, D., Schiavone, F., Appio, F.P. and Chiao, B. (2021), "How does artificial intelligence enable and enhance value co-creation in industrial markets? An exploratory case study in the healthcare ecosystem", Fournal of Business Research, Vol. 129, pp. 849-859.

Lusch, R.F., Vargo, S.L. and Gustafsson, A. (2016), "Fostering a trans-disciplinary perspectives of service ecosystems", fournal of Business Research, Vol. 69 No. 8, pp. 2957-2963.

McColl-Kennedy, J.R., Snyder, H., Elg, M., Witell, L., Helkkula, A., Hogan, S.J. and Anderson, L. (2017), "The changing role of the health care customer: review, synthesis and research agenda", fournal of Service Management, Vol. 28 No. 1, pp. 2-33.

McColl-Kennedy, J.R., Cheung, L. and Coote, L.V. (2020), "Tensions and trade-offs in multi-actor service ecosystems", Fournal of Business Research, Vol. 121, pp. 655-666.

McFarland, R.G. (2019), "A conceptual framework of macrolevel and microlevel adaptive selling theory, setting a research agenda, and suggested measurement strategies", Fournal of Personal Selling \& Sales Management, Vol. 39 No. 3, pp. 207-221.

Melchiorre, M.G., Papa, R., Rijken, M., van Ginneken, E., Hujala, A. and Barbabella, F. (2018), "eHealth in integrated care programs for people with multimorbidity in Europe: insights from the ICARE4EU project", Health Policy, Vol. 122 No. 1, pp. 53-63.

Mele, C., Nenonen, S., Pels, J., Storbacka, K., Nariswari, A. and Kaartemo, V. (2018), "Shaping service ecosystems: exploring the dark side of agency", Fournal of Service Management, Vol. 29 No. 4, pp. 521-545.

Meynhardt, T., Chandler, J.D. and Strathoff, P. (2016), "Systemic principles of value co-creation: synergetics of value and service ecosystems", fournal of Business Research, Vol. 69 No. 8, pp. 2981-2989.

Nakata, C., Izberk-Bilgin, E., Sharp, L., Spanjol, J., Cui, A.S., Crawford, S.Y. and Xiao, Y. (2019), "Chronic illness medication compliance: a liminal and contextual consumer journey", fournal of the Academy of Marketing Science, Vol. 47 No. 2, pp. 192-215. 
Neuman, W. (1997), Social Research Methods: qualitative and Quantitative Approaches, Allyn and Bacon, Needham Heights, MA.

Ng, I. and Wakenshaw, S. (2018), "Service ecosystems: a timely worldview for a connected, digital and data-driven economy", in Vargo, S.L. and Lusch, R.F. (Eds), The Sage Handbook of Service-Dominant Logic, Sage, London, pp. 99-213.

Öberg, C., Shih, T.T.Y. and Chou, H.H. (2016), "Network strategies and effects in an interactive context", Industrial Marketing Management, Vol. 52, pp. 117-127.

Orton, J.D. (1997), "From inductive to iterative grounded theory: zipping the gap between process theory and process data", Scandinavian fournal of Management, Vol. 13 No. 4, pp. 419-438.

Paschen, J., Kietzmann, J. and Kietzmann, T.C. (2019), "Artificial intelligence (AI) and its implications for market knowledge in B2B marketing", Fournal of Business $\mathcal{E}$ Industrial Marketing, Vol. 34 No. 7, pp. 1410-1419.

Patrício, L., Sangiorgi, D., Mahr, D., Čaić, M., Kalantari, S. and Sundar, S. (2020), "Leveraging service design for healthcare transformation: toward people-centered, integrated, and technology-enabled healthcare systems", Fournal of Service Management, Vol. 31 No. 5, pp. 889-909.

Peltier, J.W., Dahl, A.J. and Swan, E.L. (2020), "Digital information flows across a $\mathrm{B} 2 \mathrm{C} / \mathrm{C} 2 \mathrm{C}$ continuum and technological innovations in service ecosystems: a servicedominant logic perspective", fournal of Business Research, Vol. 121, pp. 724-734.

Petracca, F., Ciani, O., Cucciniello, M. and Tarricone, R. (2020), "Harnessing digital health technologies during and after the COVID-19 pandemic: context matters", fournal of Medical Internet Research, Vol. 22 No. 12, p. e21815.

Pettigrew, A.M. (2012), "Context and action in the transformation of the firm: a reprise", fournal of Management Studies, Vol. 49 No. 7, pp. 1304-1328.

Pop, O.M., Leroi-Werelds, S., Roijakkers, N. and Andreassen, T.W. (2018), "Institutional types and institutional change in healthcare ecosystems", fournal of Service Management, Vol. 29 No. 4, pp. 593-614.

Russo Spena, T. and Mele, C. (2019), "Practising innovation in the healthcare ecosystem: the agency of third-party actors", Fournal of Business E Industrial Marketing, Vol. 35 No. 3, pp. 390-403.

Sebastiani, R. and Anzivino, A. (2021), "Transformative value Co-creation in healthcare services in the COVID-19 era: the case of Centro cardiologico monzino", in Lee, J. and Han, H. S. (Eds), The Future of Service Post-COVID-19 Pandemic, Vol. 1, Springer, Singapore, pp. 55-73.

Shah, S.J., Schwamm, L.H., Cohen, A.B., Simoni, M.R., Estrada, J., Matiello, M., Venkataramani, A. and Rao, S.K. (2018), "Virtual visits partially replaced in-person visits in an ACO-based medical specialty practice", Health Affairs, Vol. 37 No. 12, pp. 2045-2051.

Sklyar, A., Kowalkowski, C., Sörhammar, D. and Tronvoll, B. (2019), "Resource integration through digitalisation: a service ecosystem perspective", Fournal of Marketing Management, Vol. 35 No. 11-12, pp. 974-991.
Spiggle, S. (2003), "From text to hypertext", Representing Consumers: Voices, Views and Visions, Routledge, London, p. 156.

Sust, P.P., Solans, O., Fajardo, J.C., Peralta, M.M., Rodenas, P., Gabaldà, J., Eroles, L.G., Comella, A., Muñoz, C.V., Ribes, J.S. and Monfa, R.R. (2020), “Turning the crisis into an opportunity: digital health strategies deployed during the COVID-19 outbreak", FMIR Public Health and Surveillance, Vol. 6 No. 2, p. e19106.

Thielst, C.B. (2011), "Social media: ubiquitous community and patient engagement", Frontiers of Health Services Management, Vol. 28 No. 2, pp. 3-14.

Tuzii, J. (2017), "Healthcare information technology in Italy, critiques and suggestions for European digitalization", Pharmaceuticals Policy and Law, Vol. 19 Nos 3/4, pp. 161-176.

Vargo, S.L. and Lusch, R.F. (2016), "Institutions and axioms: an extension and update of service-dominant logic", fournal of the Academy of Marketing Science, Vol. 44 No. 1, pp. 5-23.

Vargo, S.L., Akaka, M.A. and Wieland, H. (2020), "Rethinking the process of diffusion in innovation: a serviceecosystems and institutional perspective", fournal of Business Research, Vol. 116, pp. 526-534.

Verhoef, P.C., Broekhuizen, T., Bart, Y., Bhattacharya, A., Dong, J.Q., Fabian, N. and Haenlein, M. (2021), "Digital transformation: a multidisciplinary reflection and research agenda", Fournal of Business Research, Vol. 122, pp. 889-901.

Vink, J., Koskela-Huotari, K., Tronvoll, B., Edvardsson, B. and Wetter-Edman, K. (2021), "Service ecosystem design: propositions, process model, and future research agenda", Fournal of Service Research, Vol. 24 No. 2, pp. 168-186.

Wade, V. and Stocks, N. (2017), "The use of telehealth to reduce inequalities in cardiovascular outcomes in Australia and New Zealand: a critical review", Heart, Lung and Circulation, Vol. 26 No. 4, pp. 331-337.

World Health Organization (WHO) (2018), available at: www.who.int/health-topics/cardiovascular-diseases/\#tab= tab_1 (accessed January 2021).

Yin, R.K. (2009), "How to do better case studies", in Bickman, L. and Rog, D.J. (Eds), The SAGE Handbook of Applied Social Research Methods, Sage, London, Vol. 2, pp. 254-282.

\section{Further reading}

Gabbrielli, F., Bertinato, L., De Filippis, G., Bonomini, M. and Cipolla, M. (2020), "Interim provisions on telemedicine healthcare services during COVID-19 health emergency", Version of April 13, 2020, ii, 29 p. Rapporti ISS COVID-19 n. $12 / 2020$ (in Italian).

Spyglass Consulting Group (2019), "Trends in remote patient monitoring 2019", available at: www.spyglass-consulting. com/wp_RPM_2019.html (accessed January 2021).

\section{Corresponding author}

Alessia Anzivino can be contacted at: alessia.anzivino@ unicatt.it 